\title{
Exercise, ageing and the lung
}

\author{
Michael A. Roman ${ }^{1}$, Harry B. Rossiter $\mathbb{1}^{2,3}$ and Richard Casaburi² \\ Number 9 in the series "Multimorbidity and the lung" \\ Edited by L.M. Fabbri and J.M. Drazen
}

\begin{abstract}
Affiliations: ${ }^{1}$ Division of Respiratory Medicine, Rockyview Hospital, University of Calgary, Calgary, AB, Canada. ${ }^{2}$ Rehabilitation Clinical Trials Center, Division of Respiratory and Critical Care Physiology and Medicine, Los Angeles Biomedical Research Institute, Torrance, CA, USA. ${ }^{3}$ Faculty of Biological Sciences, University of Leeds, Leeds, UK.
\end{abstract}

Correspondence: Richard Casaburi, Rehabilitation Clinical Trials Center, Los Angeles Biomedical Research Institute at Harbor-UCLA Medical Center, 1124 W Carson St. Torrance, CA 90502, USA.

E-mail: casaburiducla.edu

ABSTRACT This review provides a pulmonary-focused description of the age-associated changes in the integrative physiology of exercise, including how declining lung function plays a role in promoting multimorbidity in the elderly through limitation of physical function. We outline the ageing of physiological systems supporting endurance activity: 1) coupling of muscle metabolism to mechanical power output; 2) gas transport between muscle capillary and mitochondria; 3) matching of muscle blood flow to its requirement; 4) oxygen and carbon dioxide carrying capacity of the blood; 5) cardiac output; 6) pulmonary vascular function; 7) pulmonary oxygen transport; 8) control of ventilation; and 9) pulmonary mechanics and respiratory muscle function. Deterioration in function occurs in many of these systems in healthy ageing. Between the ages of 25 and 80 years pulmonary function and aerobic capacity each decline by $\sim 40 \%$. While the predominant factor limiting exercise in the elderly likely resides within the function of the muscles of ambulation, muscle function is (at least partially) rescued by exercise training. The age-associated decline in pulmonary function, however, is not recovered by training. Thus, loss in pulmonary function may lead to ventilatory limitation in exercise in the active elderly, limiting the ability to accrue the health benefits of physical activity into senescence.

@ERSpublications

Exercise performance depends on integrated organ-system response, each subject to differential age-related decline http://ow.ly/YRNh3022S7w

Received: Feb 152016 | Accepted after revision: June 272016 | First published online: Oct 62016

Previous articles in this series: No. 1: Faner R, Cruz T, López-Giraldo A, et al. Network medicine, multimorbidity and the lung in the elderly. Eur Respir J 2014; 44: 775-788. No. 2: Divo MJ, Martinez CH, Mannino DM. Ageing and the epidemiology of multimorbidity. Eur Respir J 2014; 44: 1055-1068. No. 3: MacNee W, Rabinovich RA, Choudhury G. Ageing and the border between health and disease. Eur Respir J 2014; 44: 1332-1352. No. 4: Carraro S, Scheltema N, Bont L, et al. Early-life origins of chronic respiratory diseases: understanding and promoting healthy ageing. Eur Respir J 2014; 44: 1682-1696. No. 5: Chacko A, Carpenter DO, Callaway L, et al. Early-life risk factors for chronic nonrespiratory diseases. Eur Respir J 2015; 45: 244-259. No. 6: Barnes PJ. Mechanisms of development of multimorbidity in the elderly. Eur Respir J 2015; 45: 790-806. No. 7: Rodriguez-Roisin R, Bartolome SD, Huchon G, et al. Inflammatory bowel diseases, chronic liver diseases and the lung. Eur Respir J 2016; 47: 638-650. No. 8: Spagnolo P, Cordier J-F, Cottin V. Connective tissue diseases, multimorbidity and the ageing lung. Eur Respir J 2016; 47: 1535-1558.

Conflict of interest: None declared.

Copyright @ERS 2016 


\section{Introduction}

Human ageing is a condition satisfying four principles: it is intrinsic, universal, progressive and usually detrimental to the host [1]. The proportion of the world's population over the age of 60 years increased from $9.2 \%$ in 1990 to $11.7 \%$ in 2013 and is projected to be $21.1 \%$, or 2 billion people, by 2050 [2]. Ageing is associated with loss of physical function. The complex interplay between age-associated reduction in habitual physical activity and the intrinsic ageing processes complicates interpretation of the aetiology of physical function decline. Nevertheless, that physical inactivity is a primary cause of most chronic diseases [3] means that ability to maintain physical function into older age is vital to extend the time lived in optimal health: the "healthspan" [4]. Increasing older adults' healthspan could dramatically lessen the individual and societal impact of an ageing population. Indeed, prevalence of multimorbidity (two or more long-term disorders) is much greater in the elderly: present in 65\% of individuals aged 65-84 years, and $82 \%$ of people above 85 years old [5]. This review will explore contributors to exercise limitation in senescence, with a special focus on the lung.

Muscular exercise poses a systemic stress to homeostasis that demands an integrated multi-organ response. While physical activity was a key evolutionary stressor that contributed to shaping structure and function of human organ systems, prevalence of both chronic inactivity and increasing longevity poses a new challenge for the modern human to meet systemic demands of exercise into old age. Poor performance on cycle, treadmill or endurance walking tests in old age indicates proximity to future health decline [6]. This suggests a fundamental connection between aerobic capacity (maximal oxygen uptake $\left(V^{\prime} \mathrm{O}_{2} \max \right)$ ) and longevity. Animal studies of artificial selective breeding for running capacity show that high $V^{\prime} \mathrm{O}_{2} \max$ is associated with an $25 \%$ survival increase, lower mean arterial pressure, circulating cholesterol and triglycerides, and increased glucose tolerance, among many other health-associated effects [7]. Interestingly, while the lung is often touted as "overbuilt" for exercise, selective breeding for aerobic capacity hints otherwise. Allometrically scaled lung volume is greater in rats bred for high $V^{\prime} \mathrm{O}_{2} \max$ while, at maximal exercise, alveolar ventilation and effective pulmonary diffusing capacity are greater, and arterial $\mathrm{CO}_{2}$ partial pressure $\left(\mathrm{PaCO}_{2}\right)$ and pulmonary vascular resistance are less than in rats bred for low $V^{\prime} \mathrm{O}_{2} \max$ [8]. These findings support case reports in humans that supra-normal pulmonary function is required to allow adequate breathing reserve for youthful $V^{\prime} \mathrm{O}_{2} \max$ maintenance into old age [9].

$V^{\prime} \mathrm{O}_{2} \max$ declines with age (figure 1a) [12-15]. This is likely related, in part, to physical inactivity co-incident with advancing age: octogenarian endurance athletes can maintain $V^{\prime} \mathrm{O}_{2}$ max close to the median of those 40 years younger $\left(38 \mathrm{~mL} \cdot \mathrm{min}^{-1} \mathrm{~kg}^{-1}\right)$ [16] and in some cases younger still $\left(50 \mathrm{~mL} \cdot \mathrm{min}^{-1} \cdot \mathrm{kg}^{-1}\right)$ [9]. Nevertheless, cross-sectional studies suggest that $V^{\prime} \mathrm{O}_{2} \max$ declines with a rate between 0.2 and $0.5 \cdot \mathrm{mL} \cdot \mathrm{min}^{-1} \cdot \mathrm{kg}^{-1}$ year $^{-1}(\sim 0.5 \%$ per year $)$ after the age of 30 years, while longitudinal studies suggest that $V^{\prime} \mathrm{O}_{2}$ max decline may accelerate after ages $40-50$ years $[12,17]$. The 810 healthy men and women studied in the Baltimore Longitudinal Study of Aging between 1978 and 1998 (median follow-up 7.9 years) revealed that $V^{\prime} \mathrm{O}_{2}$ max decline accelerated from $\sim 0.3$ to $0.6 \%$ per year in the $20-30$-year-old group to $>2 \%$ per year in 70-79-year-age group and beyond, even when scaled to fat free mass [12]. Aetiology of accelerated loss in
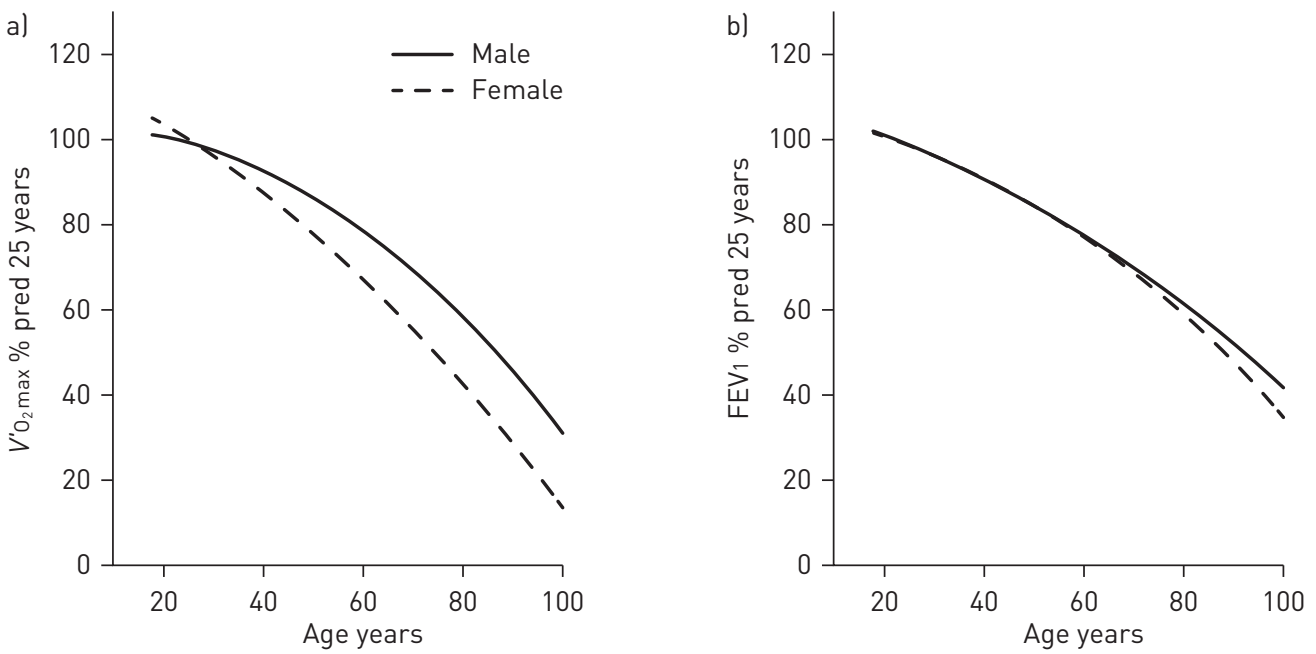

FIGURE 1 a) Decline in maximal oxygen uptake $\left(V^{\prime} 0_{2} \max \right)$ with age. $V^{\prime} 0_{2} \max$ is expressed as a \% predicted value [10] of a 25-year-old individual of average weight and height (male $177 \mathrm{~cm}$ height and $82 \mathrm{~kg}$ weight; female $164 \mathrm{~cm}$ height and $65 \mathrm{~kg}$ weight). b) Decline in forced expiratory volume in $1 \mathrm{~s}$ (FEV 1 ) with age. FEV 1 is expressed as a \% predicted value [11] for a 25-year-old individual of the same weight and height as in (a). 
older age is multifactorial, and may be consequent to greater rate of decline in stroke volume and muscle $\mathrm{O}_{2}$ extraction after 50 years of age [17-20], compared with relatively linear, and smaller magnitude, decline in maximal heart rate [12]. Despite accelerated $V^{\prime} \mathrm{O}_{2} \max$ decline in older age, greater habitual physical activity at any age is accompanied by greater $V^{\prime} \mathrm{O}_{2} \max [12,16]$. Even in octogenarians, habitual endurance exercise is associated with greater muscle oxidative capacity and expression of transcription factors associated with mitochondrial biogenesis [16]. Thus, maintaining physical activity in older age is associated with greater central (cardiac output) and peripheral (muscle $\mathrm{O}_{2}$ extraction) capacity compared with sedentary senescence.

The lactate threshold also declines with age $[21,22]$. Cross-sectional studies suggest that lactate threshold decline (both in absolute terms and relative to mass) is less rapid than $V^{\prime} \mathrm{O}_{2} \max$, such that lactate threshold $/ V^{\prime} \mathrm{O}_{2} \max$ in untrained subjects increases from $\sim 40-50 \%$ in youth to $\sim 55-70 \%$ in the $70-79$-yearage group; an effect that may be more pronounced in women than men.

Pulmonary function, however, does not respond to exercise training [23]. Therefore, age-related decline in pulmonary function (figure 1b) may become an increasingly important limiting factor for physical activity and $V^{\prime} \mathrm{O}_{2} \max$ in the elderly. Inevitable loss in lung elastic recoil associated with ageing leads to pulmonary mechanics alterations and a tendency to ventilatory limitation in older individuals. In most elderly subjects, physical activity decline may be considered protective against development of exertional symptoms and exercise limitation. However, typical lifelong pulmonary function and $V^{\prime} \mathrm{O}_{2}$ max declines are roughly proportional (figure 1), meaning that ventilatory limitation may become more noticeable in elderly who maintain high levels of physical activity.

In order to appropriately interpret constraints that the ageing lung may pose for physical function, systemic adaptations associated with older age also demand consideration. Systemic integration of physiologic mechanisms underlying exercise response was described by WASSERMAN et al. [24] in 1967 (figure 2). Physiological systems directly involved in the response to maximal aerobic exercise include: 1) coupling of muscle metabolism to mechanical power output; 2) gas transport between muscle capillary and mitochondria; 3) matching of muscle blood flow to its requirement; 4) $\mathrm{O}_{2}$ and $\mathrm{CO}_{2}$ carrying capacity of the blood; 5) cardiac output; 6) pulmonary vascular function; 7) pulmonary $\mathrm{O}_{2}$ and $\mathrm{CO}_{2}$ transport; 8) control of ventilation; and 9) pulmonary mechanics and respiratory muscle function. This review will describe ageing-associated changes in each of these links, and how declining lung function may play a role in promoting multimorbidity in the elderly through limitation of physical function.

Before embarking on an exploration of the effects of ageing on each of these physiological systems, it is worth stressing that cardiopulmonary exercise testing (CPET) can be a helpful clinical tool to evaluate the common complaint of dyspnoea on exertion in the elderly. CPET can often separate dyspnoea related to ageing from pathological causes. For example, potential contributors to increased dyspnoea in the elderly include incipient pathology, obesity, medications such as $\beta$-blockers and deconditioning. Reduced $V^{\prime} \mathrm{O}_{2}$ max and lactate threshold is seen in all these conditions, but distinguishing features may well be present. Obese subjects have increased $V^{\prime} \mathrm{O}_{2}$ during unloaded exercise but preserved $\Delta V^{\prime} \mathrm{O}_{2} / \Delta$ power output. A blunted heart rate response to exercise can be seen in $\beta$-blockade. A reduced $\Delta V^{\prime} \mathrm{O}_{2} / \Delta$ power output slope on the other hand should trigger investigations for cardiovascular abnormality. Deconditioning and ageing often yield cardiopulmonary exercise test findings that are difficult to distinguish. These observations stress the

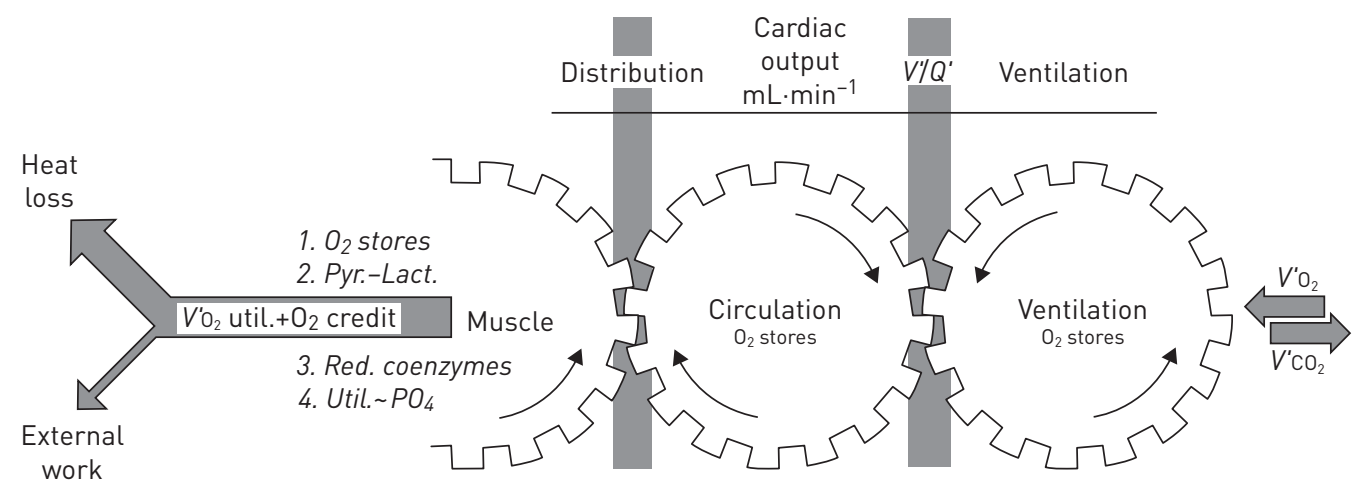

FIGURE 2 The interaction of physiological mechanisms during exercise based on the classic 1967 conceptualisation of WASSERMAN et al. [24]. The ability to perform exercise is dependent on the performance of a number of linked systems, each of which is subject to deterioration with ageing. $V^{\prime} O_{2}$ : oxygen uptake; $V^{\prime} / Q^{\prime}$ : ventilation/perfusion ratio; $V^{\prime} \mathrm{CO}_{2}$ : carbon dioxide production. Pyr.: pyrate; lact.: lactate; util.: utilisation. Reproduced from [24] with permission from the publisher. 
importance of knowledge of the appropriate inter-relationships among the pulmonary-cardio-metabolic systems during exercise, and how these relationships may change with deconditioning and with age.

\section{Coupling of muscle metabolism to mechanical power output}

The transfer of metabolic to mechanical power output at rates necessary to meet sustained exercise task requirements can be usefully considered in three stages: 1) coupling of mitochondrial oxygen consumption to ATP production (mitochondrial coupling); 2) coupling of ATP hydrolysis to mechanical power production (mechanical coupling); and 3) economy of application of mechanical power to fulfil task requirements (biomechanic coupling or "skill"). Ageing influences each of these steps.

Muscle size, architecture and metabolism are altered with advancing adult age [25]. Limb muscles, particularly large locomotor muscles, are $25-35 \%$ smaller in older age and have more fat and connective tissue than those of younger individuals [26]. This decline is accompanied by a $30-40 \%$ decrease in muscle fibre number between the second and eighth decades [27]. Type II (fast-twitch) fibres are 10-40\% smaller in the elderly, while type I (slow-twitch) fibre size is less affected. Remodelling of motor units associated with type IIx fibre loss [28], selective type IIa fibre denervation and collateral re-innervation of type I muscle fibres, results in type I fibre grouping in elderly muscle. This contributes to altered biomechanics of locomotor activity, reducing skill and increasing energy cost [29-32]. An additional component of skill deficit and muscle weakness in the elderly is disruption of excitation-contraction coupling, likely due to neuromuscular junction function loss, dihydropyridine receptor loss, impaired calcium release, and oxidative modification of myosin [33,34]. Overall, these changes reduce available muscle mass for maximal aerobic exercise, and can lower economy of its application for external locomotion (impaired biomechanical coupling) [35].

Whether changes occur in mitochondrial and mechanical coupling of elderly muscles is more controversial. At the fibre level, total mitochondrial content tends to be reduced in both type I and II elderly fibres [36, 37]. Sensitisation to permeability transition and release of mitochondrial-derived pro-apoptotic factors may be responsible [38]. Importantly, reduced mitochondrial oxidative capacity is not fully reversible by endurance training after late middle age [39-41], and overall mitochondrial content in quadriceps muscle of 70-80 year olds, estimated using magnetic resonance spectroscopy, is correlated with $V^{\prime} \mathrm{O}_{2} \max$ reduction [42]. Mild mitochondrial uncoupling of oxidative muscle fibres, possibly in response to age-associated oxidative stress increase, is proposed as a protective mechanism contributing to the relative longevity of the most active fibres [43]. It is unclear, however, whether reduction in mitochondrial coupling, observed in resting muscle, is maintained during exercise. Additionally, an $\sim 37 \%$ increase in ATP cost of power production (reduced mechanical coupling) is proposed in 70-79-year-olds based on magnetic resonance spectroscopic measurements of plantar flexion exercise [44], perhaps consequent to slower contractile relaxation, greater ATP cost of ion transport, and/or greater instantaneous stiffness (reduction in elasticity) in single fibres and whole muscles of elderly participants [45-47]. The effect of this mitochondrial and mechanical uncoupling, observed in small muscle groups, would increase the $\mathrm{O}_{2}$ cost of power production during exercise. This, however, appears not to be the case in cycle ergometry in elderly humans up to 80 years old, for whom $\mathrm{O}_{2}$ cost is unchanged compared with the young $\left(\sim 10 \mathrm{~mL} \mathrm{~min}{ }^{-1} \cdot \mathrm{W}^{-1}\right)$ [48]. Conversely, some males aged $70-79$ years were found to have reduced ATP cost of force production during electrically evoked plantar flexion exercise [49] and eight, non-smoking, female centenarians, actually showed lower $\mathrm{O}_{2}$ cost of power production during incremental exercise than young controls [50]. These findings are consistent with improved mechanical or mitochondrial efficiency during exercise in the very old: an adaptation that may offset the influence of decreasing lung function with age [50]. However, $\Delta V^{\prime} \mathrm{O}_{2} / \Delta$ power output slope in incremental exercise is sensitive to both kinetics and efficiency of oxidative phosphorylation [51], and it seems plausible that slowed $V^{\prime} \mathrm{O}_{2}$ kinetics in the elderly [52] may increase the contribution of substrate level phosphorylation to ATP provision (phosphocreatine breakdown and glycogenolysis accumulating lactate) during incremental exercise in these centenarians. Precise determination of mitochondrial and mechanical efficiency in the very old awaits resolution.

Overall, therefore, reduced mass and mitochondrial content in elderly locomotor muscles limit maximal power output and aerobic capacity and thus greatly reduce total ventilatory demand at $V^{\prime} \mathrm{O}_{2} \max$ compared with younger individuals. Muscle fibrosis, reduced elasticity and reduced biomechanical coupling may, however, contribute to increasing locomotor activity ATP cost, and thus contribute to increasing ventilatory requirement at any given submaximal power output [53].

\section{Gas transport between muscle capillary and mitochondria}

Diffusive $\mathrm{O}_{2}$ transport between muscle capillary and mitochondria is an important site of limitation to maximal $\mathrm{O}_{2}$ flux [54-56]. Diffusive $\mathrm{O}_{2}$ conductance is dependent on several variables including muscle 
capillarity (specifically, area of apposition between capillary and fibre, and mean distance between capillary and mitochondrion over which $\mathrm{O}_{2}$ has to diffuse), capillary haematocrit (red blood cell volume contacting muscle capillaries), gas solubility (as influenced by muscle structural variations, such as increased lipid concentration that facilitates $\mathrm{O}_{2}$ diffusion), temperature and muscle myoglobin and mitochondrial concentrations. Of these, the main site of resistance to diffusive $\mathrm{O}_{2}$ flux in muscle is likely to be the distance between haemoglobin and muscle sarcolemma [57, 58]. Myoglobin spectroscopy measurements in exercising human muscle $[59,60]$ show a large drop in oxygen tension $\left(\mathrm{PO}_{2}\right)$ between capillary blood and myocyte interior, highlighting both the large resistance to $\mathrm{O}_{2}$ flux at the capillary/fibre interface and the importance of maintaining high capillary $\mathrm{PO}_{2}$ to facilitate $\mathrm{O}_{2}$ diffusion.

In this context, recent re-analysis of data from the seminal 1966 Dallas Bedrest Study is pertinent [61]. Muscular and cardiovascular responses to exercise were established in five healthy 20 year-old men subjected to 3 weeks of supine bedrest followed by 8 weeks of high-intensity endurance exercise training [18], and reassessed after 40 years follow-up $[17,19,20]$. Longitudinal $V^{\prime} \mathrm{O}_{2}$ max decline $(\sim 25 \%)$, accelerating after age 50 , was similar to the decline seen following 3 weeks of bedrest in youth, and was associated with reductions in both convective $\mathrm{O}_{2}$ delivery $\left(\sim 10 \%\right.$ reduction in peak cardiac output, stroke volume, heart rate) and $\mathrm{O}_{2}$ extraction $\left(\sim 18 \%\right.$ reduction in arterio-venous $\mathrm{O}_{2}$ concentration difference). This age-associated reduction in $V^{\prime} \mathrm{O}_{2} \max$ would also be sensitive to reductions in muscle $\mathrm{O}_{2}$ diffusing capacity [61], should muscle capillarity regression exceed decline in muscle oxidative capacity in older age. However, changes in human muscle capillarity in the elderly are equivocal: $\sim 10-30 \%$ lower capillary/fibre ratio in older muscles is common, either in cross-sectional studies or across 12 years of ageing between mid-60s to mid-70s [30,62-64]. On the other hand, capillary geometry and heamatocrit, determined in young and old Fischer $344 \times$ Brown Norway hybrid rats, appear unaffected by ageing, with an increase in red blood cell flux compensating for the potential reduction in convective $\mathrm{O}_{2}$ delivery imposed by reduced capillarity, at least at rest [65]. During exercise, a lower microvascular $\mathrm{PO}_{2}$ in the elderly (either by fluorescence quenching in rat or near-infrared spectroscopy in human muscles) suggest that blood-to-tissue $\mathrm{O}_{2}$ movement may be impaired placing greater reliance on substrate-level phosphorylation during exercise [66-69]. However, the fractional contribution of glycogenolysis and phosphocreatine breakdown to total ATP production is similar during maximal aerobic exercise in muscle from old and young participants, though this was observed in plantar flexion exercise where relative perfusion $\left(Q^{\prime}\right)$ of active muscle is much greater than during locomotor exercise [44]. Therefore, considering that age-associated capillary rarefaction is somewhat less than the decrease in oxidative capacity of elderly muscle, it seems unlikely that anatomic size of capillary/fibre interface and $\mathrm{O}_{2}$ diffusional conductance plays a major role in limiting muscle aerobic performance in the elderly [70].

$\mathrm{CO}_{2}$ is approximately 20-times more diffusible than $\mathrm{O}_{2}$ in biological tissues, and high-capillary $\mathrm{CO}_{2}$ concentration may facilitate capillary oxyhaemoglobin unloading. Slowed kinetics of oxidative metabolism in the elderly require greater phosphocreatine breakdown for a given power output, and ensuing transient intramuscular alkalosis contributes to temporally slowing kinetics of $\mathrm{CO}_{2}$ output relative to its production $[44,49,71,72]$. This, together with intra- and extra-muscular $\mathrm{CO}_{2}$ buffers, slows muscular $\mathrm{CO}_{2}$ production $\left(V^{\prime} \mathrm{CO}_{2}\right)$ kinetics compared with those of $V^{\prime} \mathrm{O}_{2}$, and therefore may lessen ventilatory demands for $\mathrm{CO}_{2}$ clearance. Interestingly, expression of monocarboxylate lactate transporters 1 and 4 , and the ratio of oxidative to glycolytic enzyme activity, are increased in older muscles, independent of physical activity $[73,74]$. These adaptations may help ameliorate intramuscular acidosis and increase muscle fatigue resistance in high-intensity exercise in the elderly [75], but accelerate blood lactate appearance and onset of increased ventilatory demands associated with systemic metabolic acidosis [76]. Consequently, potential benefit from increased proton sequestration rate by phosphocreatine breakdown slowing $\mathrm{CO}_{2}$ flux towards the lung may be moderated by enhanced lactate and proton transport rate, contributing to driving ventilatory compensation for metabolic acidosis as $V^{\prime} \mathrm{O}_{2} \max$ is approached. On balance, therefore, the influence of the aged muscle/capillary interface on exercise ventilatory demands is likely small.

\section{Matching of muscle blood flow to its requirement}

Although age-associated muscle microvascular anatomy changes may be less influential than reduced mitochondrial function in limiting maximal aerobic capacity in the elderly [70], there is strong evidence that muscle blood flow is attenuated during submaximal large muscle mass or locomotor exercise in older humans ( $~ 55-80$ years) [77, 78]. The locus of attenuated increase in active muscle blood flow in the elderly, which is accomplished through a combination of systemic sympatho-excitation and local metabolically mediated vasodilatation, is controversial. However, a sex difference may exist such that older oestrogen-deficient women are particularly prone to blunting of leg vasodilator responsiveness and more rapid muscle deoxygenation compared with younger controls [79-86]. Importantly, this disruption impairs the ability of elderly muscle to deliver $\mathrm{O}_{2}$ in appropriate proportion to its requirement $\left(Q^{\prime} / V^{\prime} \mathrm{O}_{2}\right.$ ratio), which may contribute to transient microvascular deoxygenation during submaximal exercise and increased demand for substrate level phosphorylation [85, 87-89]. Reduced amplitude and kinetics of cholinergic, shear stress 
and endothelial-mediated relaxation, particularly in feed arteries of oxidative muscles, has been implicated $[90,91]$; although the effect of older age on reactivity of muscle microvessels varies with branch order and vasoactive stimulus [92]. Response to metabolic dilators is also attenuated in the elderly, e.g. ATP-induced vasodilatation is lower in the sedentary elderly [93], although whether alterations in nitric oxide (NO) contribute to limiting exercise hyperaemia in the elderly is debated [77]. The metabolically-activated group III/IV muscle afferent contribution to exercise hyperaemia appears to be absent in older individuals, which may further impair blood flow distribution and reduce regional $Q^{\prime} / V^{\prime} \mathrm{O}_{2}$ in the elderly [94]. $\alpha_{1}$-Adrenergic vasoconstrictor tone appears to be similar between old and young, but may be less attenuated during exercise in the elderly simply due to lower absolute power outputs achieved [80].

While impaired exercise vasodilatation is observed in many elderly, lifelong physical activity protects against this effect [95]: only in sedentary elderly was limb muscle lactate release associated with an attenuated exercise hyperaemia. Interestingly, in men aged 62-73 years, where absolute locomotor muscle exercise hyperaemia was well preserved, a greater proportion of submaximal cardiac output was directed towards the legs at a given $V^{\prime} \mathrm{O}_{2}$ compared with 20-25 year olds $[84,96]$. This implies that competition for blood flow by other regional circulations could, at least as maximal cardiac output is approached, attenuate locomotor muscle blood flow rise in exercising older adults [97]. This may be particularly important in relation to competition for blood flow from respiratory muscles where greater deadspace ventilation and impaired pulmonary mechanics increases work of breathing for a given $V^{\prime} \mathrm{O}_{2}$, and may contribute to limiting respiratory and/or locomotor muscle $Q^{\prime} / V^{\prime} \mathrm{O}_{2}$ in the elderly, as it can in athletes and patients with heart failure $[98,99]$.

\section{Oxygen and carbon dioxide carrying capacity of the blood}

Anaemia is prevalent in the ageing population with over $10 \%$ of individuals above age of 65 years affected [100]. Most cases of anaemia in older subjects are mild, but even mild decline in haemoglobin will decrease $\mathrm{O}_{2}$ carrying capacity and reduce $V^{\prime} \mathrm{O}_{2}$ max. Less is known about haemoglobin $\mathrm{O}_{2}$ affinity changes with ageing. A study of healthy male and female 18-89 year olds revealed an increase in the $\mathrm{PO} 2$ at which haemoglobin is half saturated $\left(P_{50}\right)$ in 60-89 year olds compared with 18-39 year olds, in keeping with age-related haemoglobin $\mathrm{O}_{2}$ affinity decrease. There was no significant change in 2,3-diphosphoglycerate concentration seen in this population [101]. Other work has shown that haemoglobin $\mathrm{O}_{2}$ affinity does not appear related to age in men [102]. There seems to be no data available regarding blood $\mathrm{CO}_{2}$ carrying capacity or buffering capacity changes with ageing.

\section{Cardiac output}

Maximal cardiac output decreases with age $[12,13]$. Decline in maximal heart rate $\left(\sim 0.7\right.$ beats $\cdot \mathrm{min}^{-1} \cdot \mathrm{year}^{-1}$ [103]) appears to be less severe than rate of $V^{\prime} \mathrm{O}_{2} \max$ decline, suggesting that decreased sinoatrial node sensitivity to $\beta$-adrenergic stimulation in older individuals [104] is not a primary cause of aerobic capacity loss. Measurements of intrinsic heart rate, using intravenous infusions of propranolol and atropine to achieve autonomic blockade, reveal linear intrinsic heart rate decrease over ages 16-70 years [105]. Animal models show that the ageing sinoatrial node has decreased conduction velocity and contains fewer pacemaker myocytes [106]. Remaining sinoatrial myocytes demonstrate altered ion channel activity, leading to depressed excitability and consequently lower heart rate [106]. Similar changes may occur in ageing human sinoatrial myocytes, but further study is needed.

Ageing hearts may utilise a different mechanism to increase stroke volume during exercise than younger hearts. In elderly subjects, end-diastolic volume increases with exercise with minimal change in end-systolic volume; while in younger individuals, the increase in stroke volume with exercise is primarily due to a decrease in end-systolic volume [107]. Increasing end-diastolic volume may lead to larger stroke volume increase during exercise in older subjects, mitigating the influence of peak heart rate decline [107]. Age does not alter the cardiac output $-V^{\prime} \mathrm{O}_{2}$ relationship although, for a given cardiac output, older subjects have lower leg blood flow [108].

Peak cardiac output falls 25\% with age [12]. Despite significant structural heart changes with age [109-111], global left ventricle systolic function appears unaffected by healthy ageing [112-114]. Peak stroke volume also appears largely unchanged throughout life [111]. If one accepts a 50\% drop in $V^{\prime} \mathrm{O}_{2}$ max from ages $20-80$ years [12], 25\% may be attributable to cardiac output decline. As stroke volume response to exercise is unchanged, reduced heart rate, as well as maldistributed cardiac output (as discussed earlier), are responsible for the cardiac contribution to age-related decline in $V^{\prime} \mathrm{O}_{2}$ max. The exercise cardiac response of the ageing individual has been likened to that of a young person on $\beta$-blockers [107].

\section{Pulmonary vascular function}

Ageing-related pulmonary circulation changes influence exercise response in the elderly subject. Pulmonary vascular stiffness increases with age $[115,116]$. Decreased pulmonary vascular compliance, along with 
decreased left ventricle compliance [114], leads to increased pulmonary arterial pressure, pulmonary wedge pressure and pulmonary vascular resistance in older individuals [117, 118]. Pulmonary arterial pressure increase appears to be secondary to vascular stiffening and decreased left ventricle compliance [118].

In a recent right heart catheterisation study, subjects older than 55 years showed resting haemodynamics similar to those of younger individuals. However, significant differences developed during exercise. The older group displayed lower cardiac output and greater mean pulmonary arterial pressure. Increased mean pulmonary arterial pressure during exercise with advancing age was the consequence of increased pulmonary vascular resistance and elevated left ventricle filling, due to age-related diastolic dysfunction [119].

\section{Pulmonary oxygen transport}

The assumption that arterial $\mathrm{O}_{2}$ partial pressure $\left(\mathrm{PaO}_{2}\right)$ declines at a constant rate between ages 20 and 100 years is founded on prediction equations based on a small number of individuals above age 60 years [120]. These equations may underestimate values for elderly subjects, with a wide prediction range of $63-84 \mathrm{mmHg}$ for an 82-year-old subject [120]. There is evidence to the contrary: BLom et al. [121] reported a plateau in $\mathrm{PaO}_{2}$ decline after age 70 years. Similarly, other recent studies show age-related decline in $\mathrm{PaO}_{2}$ between ages 40 and 74 years with no significant association between $\mathrm{PaO}_{2}$ and age greater than 70 or 74 years [122-124]. There is potential for survival bias in these results, however, as individuals with lower $\mathrm{PaO}_{2}$ may die earlier $[125,126]$. There are also sex differences for $\mathrm{PaO}_{2}$ in the elderly population. A well-done study by HARDIE et al. [123] demonstrated a mean $\mathrm{PaO}_{2}$ of $77 \mathrm{mmHg}$ (lower 95\% confidence limit of $62 \mathrm{mmHg}$ ) and $73.5 \mathrm{mmHg}$ (lower $95 \%$ confidence limit of $59.6 \mathrm{mmHg}$ ), respectively, for men and women over age 70 years.

$\mathrm{PaO}_{2}$ changes with ageing may be mechanistically related to gas diffusion properties of the lung and also to ventilation-perfusion distribution. There appears to be little effect on exercise gas exchange capabilities in older individuals, as exercise-induced arterial hypoxaemia is infrequent. However, exercise-induced hypoxaemia occurs more frequently in highly fit elderly individuals [23]. The mechanism is not known, but plausibly may be related to physiological changes noted above, and the high power outputs achieved in fit individuals (and therefore greater cardiac output and reduced capillary transit time), compared with elderly subjects of average fitness. As discussed below, increased alveolar deadspace and increased alveolar ventilation $\left(V^{\prime}\right)$ to pulmonary perfusion $\left(V^{\prime} / Q^{\prime}\right)$ mismatch in older subjects likely contribute to exercise-induced hypoxaemia seen in elderly athletes.

\section{Pulmonary trans-capillary gas diffusion}

Ageing leads to decreased capacity for pulmonary gas exchange, reflected in decline in diffusing capacity of the lung for carbon monoxide (DLCO) [127]. DLCO decline may be in part related to gradual reduction in alveolar-capillary density to alveolar diameter ratio in the older lung, along with decreased pulmonary capillary blood volume and increased $V^{\prime} / Q^{\prime}$ mismatch that are seen in the elderly [128].

\section{Matching of ventilation to perfusion}

Smaller studies have demonstrated that ageing results in an increase in lung areas with high $V^{\prime} / Q^{\prime}$ (physiological deadspace) and low $V^{\prime} / Q^{\prime}$ (shunt) $[129,130]$. Older subjects have shown increased alveolar to arterial $\mathrm{PO}_{2}$ difference $\left(\mathrm{PA}_{\mathrm{A}-\mathrm{aO}}\right)$ [131, 132]. $\mathrm{PA}-\mathrm{aO}_{2}$ can be widened by development of right-to-left shunting, diffusion limitation, or $V^{\prime} / Q^{\prime}$ mismatch. CARDus et al. [133] attempted to determine whether increasing $V^{\prime} / Q^{\prime}$ mismatch with age causes age-related $\mathrm{PaO}_{2}$ decline and found a small $\mathrm{PaO}_{2}$ decrease with age $\left(6 \mathrm{mmHg}\right.$ between ages 20 and 71 years) that was explained by a small $V^{\prime} / Q^{\prime}$ mismatch increase. Increased intra-pulmonary shunting (low $V^{\prime} / Q^{\prime}$ ) did not appear to contribute to lower $P_{\mathrm{aO}_{2}}$. Unfortunately, this was a relatively young population: only four of 64 subjects were above age 60 years. As closing volume does not equal functional residual capacity until the age of 65 years [134], it is possible there may be additional low $V^{\prime} / Q^{\prime}$ (shunt) units in more elderly subjects.

\section{Distribution of ventilation}

Deadspace to tidal volume ratio $(V \mathrm{D} / V \mathrm{~T})$ is elevated at rest in older individuals. $V \mathrm{D} / V \mathrm{~T}$ decreases with exercise but the nadir value is higher in older than in younger subjects. In young athletes, maximal exercise $V \mathrm{D} / V \mathrm{~T}$ averages $13 \%$, while in older subjects, $V \mathrm{D} / V_{\mathrm{T}}$ averages $30 \%$ [135].

Ventilation is primarily distributed to the lower lung in younger subjects [136]. Xenon distribution measurement of elderly lungs reveals that in older lungs all airways are open above $65 \%$ of total lung capacity [137]. Electrical impedance tomography of aged lung demonstrates absence of posture-dependent changes in gas distribution normally seen in younger lungs [138]. As a consequence, at resting tidal volumes, ventilation to dependent lung is decreased in older individuals, leading to greater ventilation of the upper lung and increased upper lung perfusion that improves $V^{\prime} / Q^{\prime}$ matching. 


\section{Control of ventilation}

The respiratory control system adjusts minute ventilation $\left(V^{\prime} \mathrm{E}\right)$ to respond to changes in metabolic rate and other perturbations in order to maintain, as much as possible, arterial homeostastis. Resting pulmonary ventilation is adjusted to regulate $\mathrm{PaCO}_{2}$ (and thus arterial $\mathrm{pH}$ ) within a narrow range. $\mathrm{PaO}_{2}$ only becomes an appreciable ventilatory stimulus when $\mathrm{PaO}_{2}$ drops well below the normal range. Though few systematic studies have been reported, at rest the elderly appear to regulate $\mathrm{PaCO}_{2}$ within the same range as the young; $\mathrm{PaO}_{2}$ is somewhat lower mostly because of increased $V^{\prime} / Q^{\prime}$ inhomogeneity $[53,139]$.

Challenges to the respiratory control system include exercise, inhalation of hypercapnic and hypoxic mixtures and resistive and elastic loads to breathing. Of these, exercise is the most commonly encountered challenge and has, therefore, received the most study. Interestingly, though, in comparison with the relatively preserved functional characteristics of exercise ventilatory control (discussed later), the elderly exhibit substantial degradation of response to these other challenges. Response to inhaled $\mathrm{CO}_{2}$ is blunted [139-143]; BRISChETTO et al. [140] found that the $V^{\prime} \mathrm{E}-\mathrm{PaCO}_{2}$ slope was almost one-third lower in the elderly. Similarly, hypoxic response is reduced in older individuals [141-143]; Peterson et al. [143] found hypoxic ventilatory response to be reduced about 50\%. Responses to both resistive and elastic loaded breathing are also reduced [144, 145].

Alterations in exercise ventilatory response are more subtle. A consistent observation is that ventilatory response to exercise at a given $V^{\prime} \mathrm{CO}_{2}$ is elevated in elderly subjects as compared to the young [76, 140, 146-148]. InBAR et al. [147] reported cardiopulmonary responses to incremental exercise of 1424 men, 43 of whom were aged $60-70$ years. $V^{\prime} \mathrm{E} / V^{\prime} \mathrm{CO}_{2}$ was distinctly greater across metabolic rates in the older group. Similarly Poulin et al. [148] studied the incremental treadmill exercise response in 128 men and 96 women aged 55-86 years. On average, the $V^{\prime} \mathrm{E} / V^{\prime} \mathrm{CO}_{2}$ slope was $12.3 \%$ greater per decade in men and $9.3 \%$ greater per decade in women.

The source of enhanced ventilatory response can be evaluated by considering the alveolar mass balance equation: $V^{\prime} \mathrm{E} / V^{\prime} \mathrm{CO}_{2}=\mathrm{k} /\left(\mathrm{PaCO}_{2} \times(1-V \mathrm{D} / V \mathrm{~T})\right)$, where $\mathrm{k}$ is a constant. This equation dictates that the greater $V^{\prime} \mathrm{E} / V^{\prime} \mathrm{CO}_{2}$ can have only two sources: lower $\mathrm{PaCO}_{2}$ or greater $V \mathrm{D} / V \mathrm{~T}$. BRISCHETTO et al. [140] sampled arterial blood serially during incremental exercise in two older subjects and found an isocapnic response. Mummery et al. [149] drew arterial blood samples at rest and after 6 min of moderate and heavy exercise from 10 older (average age 63 years) and 10 young subjects. Moderate exercise was isocapnic, and $P_{\mathrm{aCO}_{2}}$ fell with heavy exercise (presumably in response to metabolic acidosis), with no differences between older and younger participants. Calculations using measurements of $\mathrm{PaCO}_{2}$ suggest that deadspace is greater in elderly subjects than in young [53, 149]. A review of the literature for the source of elevated deadspace ventilation reveals only inconsistent alterations in the tidal volume-breathing frequency relationship [76]. Therefore, deadspace ventilation elevation during exercise seen in the elderly seems likely related to increased alveolar deadspace.

In contrast to moderate intensity steady-state exercise responses, dynamic exercise ventilatory responses are distinctly modified in the elderly. In studies of young subjects, dynamic response of $V^{\prime} \mathrm{E}$ is closely correlated with $V^{\prime} \mathrm{CO}_{2}$ dynamics $[150,151]$, with the result that $\mathrm{PaCO}_{2}$ fluctuation during the dynamic phase of exercise is small [151]. The observation that $V^{\prime} \mathrm{E}$ kinetics are substantially slowed in the elderly (with response time constants averaging $40-56 \%$ greater than in young subjects) $[152,153]$ might suggest that $\mathrm{PaCO}_{2}$ regulation in the non-steady state is greatly degraded, but this is likely not the case. The key observation is that $V^{\prime} \mathrm{O}_{2}$ kinetics are slowed in the elderly [152-154]. This is primarily related to low muscle oxidative capacity in ageing, but may also be influenced by wider muscle $Q^{\prime} / V^{\prime} \mathrm{O}_{2}$ distribution (see above). $V^{\prime} \mathrm{O}_{2}$ kinetics are the prime determinant of $V^{\prime} \mathrm{CO}_{2}$ kinetics, with the latter being slowed with respect to the former by muscle-alkalinizing effects of phosphocreatine breakdown and fluctuation in the body's large $\mathrm{CO}_{2}$ stores [155]. Thus, $V^{\prime} \mathrm{CO}_{2}$ kinetics are also markedly slowed in the elderly $[152,153]$. Importantly, the ratio of $V^{\prime} \mathrm{E}$ and $V^{\prime} \mathrm{CO}_{2}$ time constants are somewhat greater in elderly compared to younger subjects [152, 153], implying a slightly "looser" control of $\mathrm{PaCO}_{2}$. An important observation from eight older subjects (aged 65-78 years) undergoing a rigorous exercise-training programme was that training speeded $V^{\prime} \mathrm{O}_{2}, V^{\prime} \mathrm{CO}_{2}$ and $V^{\prime} \mathrm{E}$ kinetics (each time constant was reduced by $\sim 50 \%$ ), with correlation between the change in $V^{\prime} \mathrm{E}$ and $V^{\prime} \mathrm{CO}_{2}$ time constants being strong $(r=0.65)$ [152]. This supports the concept that slower $V^{\prime} E$ kinetics in the elderly are mostly related to slowed metabolic rate kinetics, but a small degradation of $\mathrm{PaCO}_{2}$ control cannot be excluded.

\section{Pulmonary mechanics and respiratory muscle function}

With age, lung structural changes occur that affect exercise ventilatory response. These changes have the potential to contribute to decreased exercise performance and decline in $V^{\prime} \mathrm{O}_{2}$ max seen with increasing age $[10,12,147,156,157]$. The lung's ageing process is difficult to generalise, given differences in individual environmental and genetic factors that influence how an individual ages. Sex differences in lung ageing may also be significant. The increase in resting lung and residual volumes and reduced vital and 
inspiratory capacities that occur with age have been well described in the literature and are beyond this review's scope [139, 158-161].

Pulmonary function begins to decline at approximately age 25 years. In healthy non-smoking individuals, spirometric measures forced expiratory volume in $1 \mathrm{~s}$ (FEV1) and forced vital capacity (FVC) decrease by $\sim 30 \mathrm{~mL} \cdot$ year $^{-1}$ in men and $23 \mathrm{~mL} \cdot$ year $^{-1}$ in women, with accelerated loss after age 65 year [162, 163], Mean bronchial diameter also decreases with age, yielding increased airway resistance, particularly in peripheral airways [164]. Pulmonary static elastic recoil pressure decreases by approximately $0.1-0.2 \mathrm{~cm} \cdot \mathrm{year}^{-1}$ after age 20 years due to chest wall stiffness increase and lung tissue elasticity loss [165, 166]. Elasticity loss is thought to represent remodelling of both spatial arrangement and cross-linking of the lung's elastin-collagen network [167]. Elastic recoil loss leads to alteration in the expiratory portion of the maximal flow-volume loop and results in the characteristic "scalloped" loop seen in elderly non-smokers. Elastic recoil loss appears proportional to peak expiratory flow decrease with age [168].

Over time, chest wall compliance decreases due to calcification of costal cartilage, with increased prevalence of both spinal kyphosis and osteoporosis-associated vertebral fractures potentially contributing [169-171]. Obesity is prevalent in the ageing population, affecting more than one-third of adults older than 65 years [172]. Obese individuals have lower respiratory system compliance [173-175]. Expiratory reserve volume clearly decreases with increasing body mass index; functional residual capacity is reduced to a lesser extent. Total lung capacity does not appear to be affected significantly, except in extreme obesity. Decreased compliance is expected to contribute to increased dyspnoea during exercise in obese individuals $[176,177]$.

Respiratory muscle strength decreases with age [178, 179]. Maximal effort transdiaphragmatic pressure gradients in older individuals are lower than in younger subjects, reflecting decreased diaphragmatic strength $[180,181]$. In one study, diaphragm strength in the elderly was $13 \%$ less than in a younger group by maximal sniff and $23 \%$ less using cervical magnetic stimulation. Other measurements have shown $25 \%$ lower diaphragmatic strength in the elderly [181]. Strength loss does not appear related to diaphragmatic fibre type change or muscle atrophy [182-184]. Diaphragm and intercostal muscle stiffness increase with age [185], decreasing chest wall compliance. Diaphragm collagen metabolism changes (collagen concentration and cross-linking increases) appear responsible for increased stiffness [186]. Spinal kyphosis and increased chest anterior-posterior diameter that occur with age likely contribute to decreased diaphragmatic function [158].

Airspace size increases with age [187]. The term "senile emphysema" that has been used to describe this age-related pulmonary morphological change is inaccurate; although ageing results in alveolar duct enlargement and distal duct ectasia, the ageing lung does not develop alveolar wall destruction and inflammation that is a hallmark of smoking-related emphysema [188].

In healthy adults, peak ventilation during exercise typically approaches $70 \%$ of measured maximal voluntary ventilation, demonstrating appreciable breathing reserve. Ageing is associated with a greater $V^{\prime} \mathrm{E}$ and dyspnoea for a given power output (figure 3) due to mechanisms discussed earlier, including reduced lactate threshold, and increased $V \mathrm{D} / V \mathrm{~T}$ and $V^{\prime} / Q^{\prime}$ mismatching (likely reflected in the increased $V^{\prime} \mathrm{E} / V^{\prime} \mathrm{CO}_{2}$ ). Breathing reserve tends to decrease in athletes and with normal ageing [189]. In a recent study of 759 maximal treadmill exercise tests performed in healthy Norwegian adults aged 20-85 years, peak ventilation decrease started at ages 40-49 years [190]. While peak $V^{\prime} \mathrm{E}$ decreased, predicted maximal voluntary ventilation (based on both FEV1.35 and FEV1.40) $[156,191]$ also decreased due to age-related $\mathrm{FEV}_{1}$ reduction. This led to breathing reserve preservation. There is also an age-related decline in vital capacity that leads to relative limitation in tidal volume (figure 3), meaning, for a given ventilation, breathing frequency tends to be greater, especially at higher intensities [161, 192].

During exercise in youth, tidal volume increase is achieved through decreases in both inspiratory and expiratory reserve volumes $[193,194]$. There is initially a drop in end-expiratory lung volume (EELV) in both young and old subjects to optimise inspiratory muscle function [195]. During severe intensity exercise in fit, young athletes, expiratory flow limitation can develop [193], although increased EELV does not appear until very high rates of ventilation [23, 195]. Airway diameter decrease and static recoil pressure reduction that occur in ageing suggest that flow limitation may also become a factor limiting exercise in older individuals. Accurate measurement of expiratory flow limitation during exercise is challenging. The most common method involves demonstrating impingement of exercise flow-volume loops on the maximum-effort resting expiratory flow-volume relationship. This method, however, does not account for thoracic gas compression and may overestimate flow limitation during exercise [192, 196]. Taking several expirations at variable efforts from total lung capacity to residual volume may help correct for dynamic gas compression [196]. Using a post-exercise maximal expiratory flow-volume curve also helps by accounting for exercise-induced bronchodilation [192]. WILKIE et al. [195] reported that older 
a)
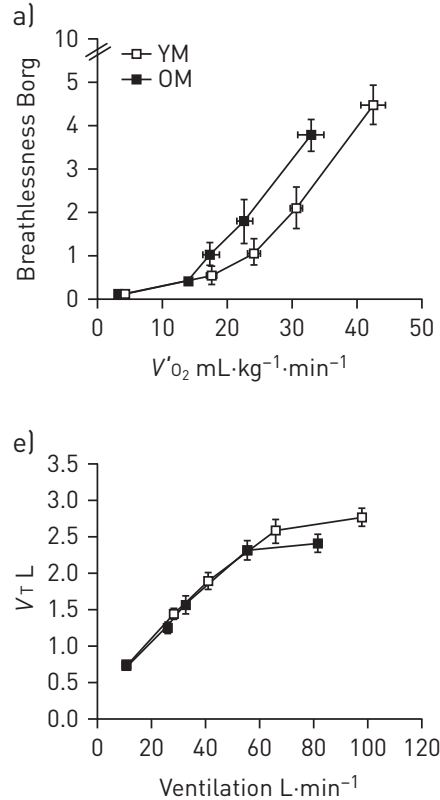

b)

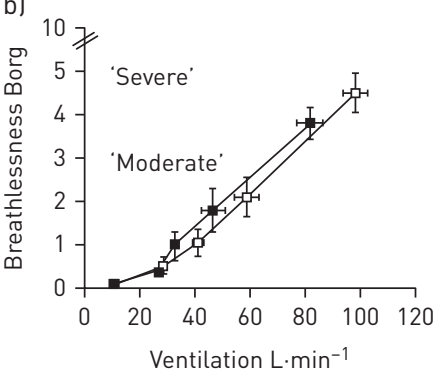

f)

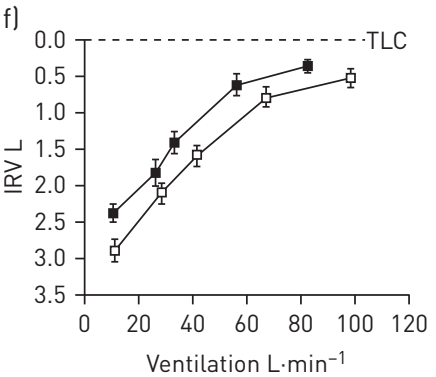

c)

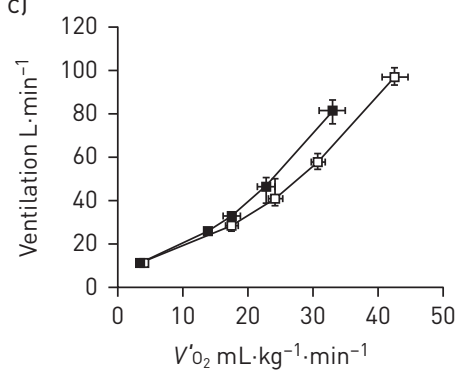

g)

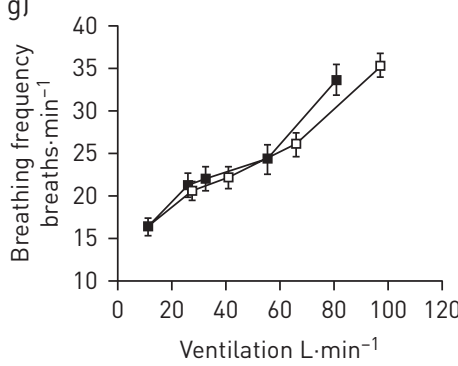

d)

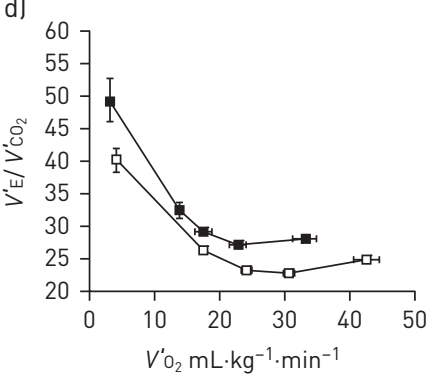

h)

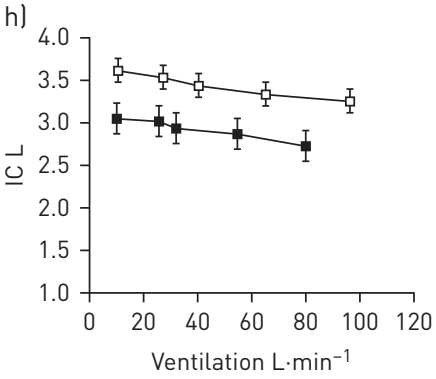

FIGURE 3 Perceptual, ventilatory and respiratory mechanical responses to incremental treadmill exercise in healthy older (OM; aged 60-80 years) compared with younger men (YM; aged 40-59 years). Data are presented as mean \pm SEM for measurements at rest, during each stage of exercise and at peak exercise. $V^{\prime} \mathrm{O}_{2}$ : oxygen uptake; $V^{\prime} \mathrm{E}$ : minute ventilation; $V^{\prime} \mathrm{CO}_{2}$ : carbon dioxide production; $V \mathrm{~T}$ : tidal volume; IRV: inspiratory reserve volume; TLC: total lung capacity; IC: inspiratory capacity. Reproduced from [161] with permission from the publisher.

women exhibit exercise expiratory flow limitation more frequently than younger women. Older subjects also report greater breathlessness and a steeper slope of the dyspnoea-power output relationship, suggesting that age-related lung changes have symptomatic consequences (figure 3). Interestingly, this study found an EELV increase at power outputs between $80-100 \% V^{\prime} \mathrm{O}_{2} \max$ only in younger women. The authors hypothesise that impending flow limitation in older women may have an effect on EELV regulation [195]. This contrasts with findings of another study of trained individuals (14 men, four women aged 62-82 years) where older subjects increased EELV during moderate intensity exercise, but EELV did not increase in younger subjects until $V^{\prime} \mathrm{E}$ exceeded $110-120 \mathrm{~L} \cdot \mathrm{min}^{-1}$ [23]. Increased EELV compromises operating length-tension relationships of diaphragm and respiratory muscles, leading to less force generation capacity. Increased EELV during exercise results in the subject breathing on the flattened portion of the lung pressure-volume relationship, reducing inspiratory muscle length, increasing work of breathing and potentially decreasing inspiratory muscle endurance [192]. In line with these effects, inspiratory reserve volume is consistently lower in the elderly at rest, and remains lower, along with inspiratory capacity, for any given level of $V^{\prime}$ E compared with young subjects (figure 3), likely contributing importantly to the greater sensation of breathlessness in the elderly [161, 197, 198].

While flow limitation and EELV behave in a similar fashion during low intensity exercise in older and younger lungs, expiratory flow limitation seems to develop at lower intensity exercise in older subjects [23, $53,195]$. There may be a sex difference, with women developing expiratory flow limitation more frequently than men during high intensity exercise [199], presumably related to decreased lung size and lower maximal expiratory flow rates in women. GuenetTe et al. [200] describe an 86-year-old female lifelong competitive swimmer (former Olympian) with moderate airflow obstruction (FEV1/FVC 53\%; FEV1 54\% predicted) who continued regular exercise into old age. Despite severe ventilatory limitation (dynamic hyperinflation of $780 \mathrm{~mL}$ and end inspiratory lung volume of $96 \%$ total lung capacity) the participant only reported moderate dyspnoea and achieved $V^{\prime} \mathrm{O}_{2} \max$ of $175 \%$ predicted $\left(19.6 \mathrm{~mL} \mathrm{~kg}{ }^{-1} \mathrm{~min}^{-1}\right)$. The authors speculate reduced ventilatory requirements, breathing pattern alterations and improved respiratory muscle strength may each contribute to reduced dyspnoea in this athletic octogenarian. While only a case report, these findings emphasise that relative preservation throughout life of aerobic capacity may be possible with regular high-intensity exercise, even when expiratory flow and ventilatory limitation is present.

\section{Conclusions}

Maintaining a high level of physical activity is an important part of healthy ageing and minimisation of multimorbidity. Deterioration in various components of the multi-organ system response to exercise in the elderly conspires to make this difficult. Decreases in pulmonary system function likely contribute to exercise intolerance in healthy elderly, particularly those who maintain physical activity into senescence. 
However, loss of muscle oxidative capacity and cardiac output in sedentary elderly outstrips decline in pulmonary function, such that the relatively small contribution of pulmonary function to exercise limitation is preserved over a wide range of ages. Training programmes for muscles of ambulation remains the most effective way to retain aerobic capacity in older individuals. However, the degree to which maintenance of training past 70 years of age, which is associated with considerable health-benefits, causes encroachment upon pulmonary limits requires further study.

\section{Acknowledgements}

R. Casaburi holds the Grancell/Burns Chair in the Rehabilitative Sciences.

\section{References}

1 Strehler BL, Mark DD, Mildvan AS. GEE MV: Rate and magnitude of age pigment accumulation in the human myocardium. J Gerontol 1959; 14: 430-439.

2 Sander M, Oxlund B, Jespersen A, et al. The challenges of human population ageing. Age Ageing 2015; 44: $185-187$.

3 Booth FW, Roberts CK, Laye MJ. Lack of exercise is a major cause of chronic diseases. Compr Physiol 2012; 2: 1143-1211.

$4 \quad$ Van Norman KA. Exercise programming for older adults. Champaign, Human Kinetics, 1995.

5 Chatterji S, Byles J, Cutler D, et al. Health, functioning, and disability in older adults-present status and future implications. Lancet 2015; 385: 563-575.

6 Myers J, Prakash M, Froelicher V, et al. Exercise capacity and mortality among men referred for exercise testing. N Engl J Med 2002; 346: 793-801.

7 Koch LG, Kemi OJ, Qi N, et al. Intrinsic aerobic capacity sets a divide for aging and longevity. Circ Res 2011; 109: $1162-1172$.

8 Kirkton SD, Howlett RA, Gonzalez NC, et al. Continued artificial selection for running endurance in rats is associated with improved lung function. J Appl Physiol (1985) 2009; 106: 1810-1818.

9 Karlsen T, Leinan IM, Baekkerud FH, et al. How to be 80 year old and have a $V^{\prime} \mathrm{O}_{2} \max$ of a 35 year old. Case Rep Med 2015; 2015: 909561.

10 Glaser S, Koch B, Ittermann T, et al. Influence of age, sex, body size, smoking, and beta blockade on key gas exchange exercise parameters in an adult population. Eur J Cardiovasc Prev Rehabil 2010; 17: 469-476.

11 Hankinson JL, Odencrantz JR, Fedan KB. Spirometric reference values from a sample of the general U.S population. Am J Respir Crit Care Med 1999; 159: 179-187.

12 Fleg JL, Morrell CH, Bos AG, et al. Accelerated longitudinal decline of aerobic capacity in healthy older adults. Circulation 2005; 112: 674-682.

13 Rosen MJ, Sorkin JD, Goldberg AP, et al. Predictors of age-associated decline in maximal aerobic capacity: a comparison of four statistical models. J Appl Physiol (1985) 1998; 84: 2163-2170.

14 Ogawa T, Spina RJ, Martin WH III, et al. Effects of aging, sex, and physical training on cardiovascular responses to exercise. Circulation 1992; 86: 494-503.

15 Toth MJ, Gardner AW, Ades PA, et al. Contribution of body composition and physical activity to age-related decline in peak VO2 in men and women. J Appl Physiol (1985) 1994; 77: 647-652.

16 Trappe S, Hayes E, Galpin A, et al. New records in aerobic power among octogenarian lifelong endurance athletes. J Appl Physiol (1985) 2013; 114: 3-10.

17 McGavock JM, Hastings JL, Snell PG, et al. A forty-year follow-up of the Dallas Bed Rest and Training study: the effect of age on the cardiovascular response to exercise in men. J Gerontol A Biol Sci Med Sci 2009; 64: 293-299.

18 Saltin B, Blomqvist G, Mitchell JH, et al. Response to exercise after bed rest and after training. Circulation 1968; 38: 5 Suppl, VII1-VI78.

19 McGuire DK, Levine BD, Williamson JW, et al. A 30-year follow-up of the Dallas Bedrest and Training Study: I. Effect of age on the cardiovascular response to exercise. Circulation 2001; 104: 1350-1357.

20 McGuire DK, Levine BD, Williamson JW, et al. A 30-year follow-up of the Dallas Bedrest and Training Study: II. Effect of age on cardiovascular adaptation to exercise training. Circulation 2001; 104: 1358-1366.

21 Pollock RD, Carter S, Velloso CP, et al. An investigation into the relationship between age and physiological function in highly active older adults. J Physiol 2015; 593: 657-680.

22 Neder JA, Nery LE, Castelo A, et al. Prediction of metabolic and cardiopulmonary responses to maximum cycle ergometry: a randomised study. Eur Respir J 1999; 14: 1304-1313.

23 McClaran SR, Babcock MA, Pegelow DF, et al. Longitudinal effects of aging on lung function at rest and exercise in healthy active fit elderly adults. J Appl Physiol (1985) 1995; 78: 1957-1968.

24 Wasserman K, Van Kessel AL, Burton GG. Interaction of physiological mechanisms during exercise. J Appl Physiol 1967; 22: 71-85.

25 Miljkovic N, Lim JY, Miljkovic I, et al. Aging of skeletal muscle fibers. Ann Rehabil Med 2015; 39: 155-162.

26 Goodpaster BH, Carlson CL, Visser M, et al. Attenuation of skeletal muscle and strength in the elderly: The Health ABC Study. J Appl Physiol (1985) 2001; 90: 2157-2165.

27 Lexell J. Human aging, muscle mass, and fiber type composition. J Gerontol A Biol Sci Med Sci 1995; 50: 11-16.

28 Wang Y, Pessin JE. Mechanisms for fiber-type specificity of skeletal muscle atrophy. Curr Opin Clin Nutr Metab Care 2013; 16: 243-250.

29 VanSwearingen JM, Studenski SA. Aging, motor skill, and the energy cost of walking: implications for the prevention and treatment of mobility decline in older persons. J Gerontol A Biol Sci Med Sci 2014; 69: 1429-1436.

30 Frontera WR, Hughes VA, Fielding RA, et al. Aging of skeletal muscle: a 12-yr longitudinal study. J Appl Physiol (1985) 2000; 88: 1321-1326.

31 Clark BC, Taylor JL. Age-related changes in motor cortical properties and voluntary activation of skeletal muscle. Curr Aging Sci 2011; 4: 192-199. 
Frontera WR, Suh D, Krivickas LS, et al. Skeletal muscle fiber quality in older men and women. Am J Physiol Cell Physiol 2000; 279: C611-C618.

Lowe DA, Thomas DD, Thompson LV. Force generation, but not myosin ATPase activity, declines with age in rat muscle fibers. Am J Physiol Cell Physiol 2002; 283: C187-C192.

Manini TM, Clark BC. Dynapenia and aging: an update. J Gerontol A Biol Sci Med Sci 2012; 67: 28-40.

Venturelli M, Saggin P, Muti E, et al. In vivo and in vitro evidence that intrinsic upper- and lower-limb skeleta muscle function is unaffected by ageing and disuse in oldest-old humans. Acta Physiol (Oxf) 2015; 215: 58-71. Chabi B, Ljubicic V, Menzies KJ, et al. Mitochondrial function and apoptotic susceptibility in aging skeletal muscle. Aging Cell 2008; 7: 2-12.

Carter HN, Chen CC, Hood DA. Mitochondria, muscle health, and exercise with advancing age. Physiology (Bethesda) 2015; 30: 208-223.

Hepple RT. Mitochondrial involvement and impact in aging skeletal muscle. Front Aging Neurosci 2014; 6: 211.

Ljubicic V, Joseph AM, Adhihetty PJ, et al. Molecular basis for an attenuated mitochondrial adaptive plasticity in aged skeletal muscle. Aging (Albany NY) 2009; 1: 818-830.

Ljubicic V, Hood DA. Diminished contraction-induced intracellular signaling towards mitochondrial biogenesis in aged skeletal muscle. Aging Cell 2009; 8: 394-404.

Betik AC, Thomas MM, Wright KJ, et al. Exercise training from late middle age until senescence does not attenuate the declines in skeletal muscle aerobic function. Am J Physiol Regul Integr Comp Physiol 2009; 297: R744-R755.

Santanasto AJ, Glynn NW, Jubrias SA, et al. Skeletal muscle mitochondrial function and fatigability in older adults. J Gerontol A Biol Sci Med Sci 2015; 70: 1379-1385.

Amara CE, Shankland EG, Jubrias SA, et al. Mild mitochondrial uncoupling impacts cellular aging in human muscles in vivo. Proc Natl Acad Sci USA 2007; 104: 1057-1062.

Layec G, Trinity JD, Hart CR, et al. Impact of age on exercise-induced ATP supply during supramaximal plantar flexion in humans. Am J Physiol Regul Integr Comp Physiol 2015; 309: R378-R388.

Hunter SK, Thompson MW, Ruell PA, et al. Human skeletal sarcoplasmic reticulum Ca2+ uptake and muscle function with aging and strength training. J Appl Physiol (1985) 1999; 86: 1858-1865.

Layec G, Hart CR, Trinity JD, et al. Skeletal muscle work efficiency with age: the role of non-contractile processes. Clin Sci (Lond) 2015; 128: 213-223.

Ochala J, Frontera WR, Dorer DJ, et al. Single skeletal muscle fiber elastic and contractile characteristics in young and older men. J Gerontol A Biol Sci Med Sci 2007; 62: 375-381.

DeLorey DS, Paterson DH, Kowalchuk JM. Effects of ageing on muscle $\mathrm{O}_{2}$ utilization and muscle oxygenation during the transition to moderate-intensity exercise. Appl Physiol Nutr Metab 2007; 32: 1251-1262.

Tevald MA, Foulis SA, Lanza IR, et al. Lower energy cost of skeletal muscle contractions in older humans. Am J Physiol Regul Integr Comp Physiol 2010; 298: R729-R739.

Venturelli M, Schena F, Scarsini R, et al. Limitations to exercise in female centenarians: evidence that muscular efficiency tempers the impact of failing lungs. Age (Dordr) 2013; 35: 861-870. kinetic response to ramp-incremental exercise. J Appl Physiol (1985) 2016; 120: 503-513.

Grey TM, Spencer MD, Belfry GR, et al. Effects of age and long-term endurance training on VO2 kinetics. Med Sci Sports Exerc 2015; 47: 289-298.

Johnson BD, Reddan WG, Pegelow DF, et al. Flow limitation and regulation of functional residual capacity during exercise in a physically active aging population. Am Rev Respir Dis 1991; 143: 960-967.

Wagner PD. Determinants of maximal oxygen transport and utilization. Annu Rev Physiol 1996; 58: 21-50.

Saltin B, Calbet JA. Point: in health and in a normoxic environment, $\mathrm{VO}_{2}$ max is limited primarily by cardiac output and locomotor muscle blood flow. J Appl Physiol (1985) 2006; 100: 744-745.

Wagner PD. Counterpoint: in health and in normoxic environment $\mathrm{VO}_{2} \max$ is limited primarily by cardiac output and locomotor muscle blood flow. J Appl Physiol (1985) 2006; 100: 745-747.

McAllister RM, Terjung RL. Training-induced muscle adaptations: increased performance and oxygen consumption. J Appl Physiol (1985) 1991; 70: 1569-1574.

Bebout DE, Hogan MC, Hempleman SC, et al. Effects of training and immobilization on VO2 and DO2 in dog gastrocnemius muscle in situ. J Appl Physiol (1985) 1993; 74: 1697-1703.

Richardson RS, Wary C, Wray DW, et al. MRS Evidence of adequate $\mathrm{O}_{2}$ supply in human skeletal muscle at the onset of exercise. Med Sci Sports Exerc 2015; 47: 2299-2307.

Mole PA, Chung Y, Tran TK, et al. Myoglobin desaturation with exercise intensity in human gastrocnemius muscle. Am J Physiol 1999; 277(1 Pt 2): R173-R180.

Wagner PD. A re-analysis of the 1968 Saltin et al. "Bedrest" paper. Scand J Med Sci Sports 2015; 25: Suppl 4, 83-87.

Groen BB, Hamer HM, Snijders T, et al. Skeletal muscle capillary density and microvascular function are compromised with aging and type 2 diabetes. J Appl Physiol (1985) 2014; 116: 998-1005.

Chilibeck PD, Paterson DH, Cunningham DA, et al. Muscle capillarization $\mathrm{O}_{2}$ diffusion distance, and $\mathrm{VO}_{2}$ kinetics in old and young individuals. J Appl Physiol (1985) 1997; 82: 63-69.

Coggan AR, Spina RJ, King DS, et al. Histochemical and enzymatic comparison of the gastrocnemius muscle of young and elderly men and women. J Gerontol 1992; 47: B71-B76.

Russell JA, Kindig CA, Behnke BJ, et al. Effects of aging on capillary geometry and hemodynamics in rat spinotrapezius muscle. Am J Physiol Heart Circ Physiol 2003; 285: H251-H258.

Gravelle BM, Murias JM, Spencer MD, et al. Adjustments of pulmonary $\mathrm{O}_{2}$ uptake and muscle deoxygenation during ramp incremental exercise and constant-load moderate-intensity exercise in young and older adults. J Appl Physiol (1985) 2012; 113: 1466-1475.

67 Chilibeck PD, McCreary CR, Marsh GD, et al. Evaluation of muscle oxidative potential by 31P-MRS during incremental exercise in old and young humans. Eur J Appl Physiol Occup Physiol 1998; 78: 460-465.

Costes F, Denis C, Roche F, et al. Age-associated alteration of muscle oxygenation measured by near infrared spectroscopy during exercise. Arch Physiol Biochem 1999; 107: 159-167.

Behnke BJ, Delp MD, Dougherty PJ, et al. Effects of aging on microvascular oxygen pressures in rat skeletal muscle. Respir Physiol Neurobiol 2005; 146: 259-268. 
Hepple RT, Hagen JL, Krause DJ, et al. Aerobic power declines with aging in rat skeletal muscles perfused at matched convective $\mathrm{O}_{2}$ delivery. J Appl Physiol (1985) 2003; 94: 744-751.

Tevald MA, Foulis SA, Kent JA. Effect of age on in vivo oxidative capacity in two locomotory muscles of the leg. Age (Dordr) 2014; 36: 9713.

Chuang ML, Ting H, Otsuka T, et al. Aerobically generated $\mathrm{CO}(2)$ stored during early exercise. J Appl Physiol (1985) 1999; 87: 1048-1058.

Cartee GD. Aging skeletal muscle: response to exercise. Exerc Sport Sci Rev 1994; 22: 91-120.

and unloaded rat skeletal muscle. Exp Gerontol 2009; 44: 280-288

Kent-Braun JA. Skeletal muscle fatigue in old age: whose advantage? Exerc Sport Sci Rev 2009; 37: 3-9.

Prioux J, Ramonatxo M, Hayot M, et al. Effect of ageing on the ventilatory response and lactate kinetics during incremental exercise in man. Eur J Appl Physiol 2000; 81: 100-107.

Wray DW, Richardson RS. 'Fine-tuning' blood flow to the exercising muscle with advancing age: an update Exp Physiol 2015; 100: 589-602.

Proctor DN, Parker BA. Vasodilation and vascular control in contracting muscle of the aging human Microcirculation 2006; 13: 315-327.

Poole JG, Lawrenson L, Kim J, et al. Vascular and metabolic response to cycle exercise in sedentary humans: effect of age. Am J Physiol Heart Circ Physiol 2003; 284: H1251-H1259.

Wray DW, Nishiyama SK, Richardson RS. Role of alpha-1-adrenergic vasoconstriction in the regulation of skeletal muscle blood flow with advancing age. Am J Physiol Heart Circ Physiol 2009; 296: H497-H504.

Trinity JD, Groot HJ, Layec G, et al. Passive leg movement and nitric oxide-mediated vascular function: the impact of age. Am J Physiol Heart Circ Physiol 2015; 308: H672-H679.

Barrett-O'Keefe Z, Ives SJ, Trinity JD, et al. Endothelin-A-mediated vasoconstriction during exercise with advancing age. J Gerontol A Biol Sci Med Sci 2015; 70: 554-565.

Proctor DN, Koch DW, Newcomer SC, et al. Leg blood flow and $\mathrm{VO}_{2}$ during peak cycle exercise in younger and older women. Med Sci Sports Exerc 2004; 36: 623-631.

Proctor DN, Newcomer SC, Koch DW, et al. Leg blood flow during submaximal cycle ergometry is not reduced in healthy older normally active men. J Appl Physiol (1985) 2003; 94: 1859-1869.

Parker BA, Smithmyer SL, Ridout SJ, et al. Age and microvascular responses to knee extensor exercise in women. Eur J Appl Physiol 2008; 103: 343-351.

Proctor DN, Koch DW, Newcomer SC, et al. Impaired leg vasodilation during dynamic exercise in healthy older women. J Appl Physiol (1985) 2003; 95: 1963-1970.

DeLorey DS, Kowalchuk JM, Paterson DH. Effects of prior heavy-intensity exercise on pulmonary $\mathrm{O}_{2}$ uptake and muscle deoxygenation kinetics in young and older adult humans. J Appl Physiol (1985) 2004; 97: 998-1005.

Behnke BJ, Ramsey MW, Stabley JN, et al. Effects of aging and exercise training on skeletal muscle blood flow and resistance artery morphology. J Appl Physiol (1985) 2012; 113: 1699-1708.

Murias JM, Keir DA, Spencer MD, et al. Sex-related differences in muscle deoxygenation during ramp incremental exercise. Respir Physiol Neurobiol 2013; 189: 530-536.

Park SY, Ives SJ, Gifford JR, et al. The impact of age on the vasodilatory function of human skeletal muscle feed arteries. Am J Physiol Heart Circ Physiol 2016: 310: H217-H225.

Behnke BJ, Delp MD. Aging blunts the dynamics of vasodilation in isolated skeletal muscle resistance vessels. J Appl Physiol (1985) 2010; 108: 14-20.

Sinkler SY, Segal SS. Aging alters reactivity of microvascular resistance networks in mouse gluteus maximus muscle. Am J Physiol Heart Circ Physiol 2014; 307: H830-H839.

Mortensen SP, Nyberg M, Winding K, et al. Lifelong physical activity preserves functional sympatholysis and purinergic signalling in the ageing human leg. J Physiol 2012; 590: 6227-6236.

Sidhu SK, Weavil JC, Venturelli M, et al. Aging alters muscle reflex control of autonomic cardiovascular responses to rhythmic contractions in humans. Am J Physiol Heart Circ Physiol 2015; 309: H1479-H1489.

Taddei S, Galetta F, Virdis A, et al. Physical activity prevents age-related impairment in nitric oxide availability in elderly athletes. Circulation 2000; 101: 2896-2901.

Proctor DN, Beck KC, Shen $\mathrm{PH}$, et al. Influence of age and gender on cardiac output- $\mathrm{VO}_{2}$ relationships during submaximal cycle ergometry. J Appl Physiol (1985) 1998; 84: 599-605.

Harms CA, Babcock MA, McClaran SR, et al. Respiratory muscle work compromises leg blood flow during maximal exercise. J Appl Physiol (1985) 1997; 82: 1573-1583.

Vogiatzis I, Athanasopoulos D, Habazettl $\mathrm{H}$, et al. Intercostal muscle blood flow limitation in athletes during maximal exercise. J Physiol 2009; 587: 3665-3677.

Olson TP, Joyner MJ, Dietz NM, et al. Effects of respiratory muscle work on blood flow distribution during exercise in heart failure. J Physiol 2010; 588: 2487-2501. Andres E, Serraj K, Federici L,

Tweeddale PM, Leggett RJ, Flenley DC. Effect of age on oxygen-binding in normal human subjects. Clin Sci Mol Med 1976; 51: 185-188.

Mairbaurl H, Weber RE. Oxygen transport by hemoglobin. Compr Physiol 2012; 2: 1463-1489.

Tanaka H, Monahan KD, Seals DR. Age-predicted maximal heart rate revisited. J Am Coll Cardiol 2001; 37: 153-156.

Fleg JL, Schulman S, O'Connor F, et al. Effects of acute beta-adrenergic receptor blockade on age-associated changes in cardiovascular performance during dynamic exercise. Circulation 1994; 90: 2333-2341.

Jose $\mathrm{AD}$, Collison $\mathrm{D}$. The normal range and determinants of the intrinsic heart rate in man. Cardiovasc Res 1970; 4: 160-167.

Larson ED, St Clair JR, Sumner WA, et al. Depressed pacemaker activity of sinoatrial node myocytes contributes to the age-dependent decline in maximum heart rate. Proc Natl Acad Sci USA 2013; 110: 18011-18016.

Cheitlin MD. Cardiovascular physiology-changes with aging. Am J Geriatr Cardiol 2003; 12: 9-13.

Betik AC, Hepple RT. Determinants of $\mathrm{VO}_{2}$ max decline with aging: an integrated perspective. Appl Physiol Nutr Metab 2008; 33: 130-140. 
Arbab-Zadeh A, Dijk E, Prasad A, et al. Effect of aging and physical activity on left ventricular compliance. Circulation 2004; 110: 1799-1805.

Fujimoto N, Hastings JL, Bhella PS, et al. Effect of ageing on left ventricular compliance and distensibility in healthy sedentary humans. J Physiol 2012; 590: 1871-1880.

Strait JB, Lakatta EG. Aging-associated cardiovascular changes and their relationship to heart failure. Heart Fail Clin 2012; 8: 143-164.

Lakatta EG. Arterial and cardiac aging: major shareholders in cardiovascular disease enterprises: Part III: cellular and molecular clues to heart and arterial aging. Circulation 2003; 107: 490-497.

Forman DE, Manning WJ, Hauser R, et al. Enhanced left ventricular diastolic filling associated with long-term endurance training. J Gerontol 1992; 47: M56-M58.

Bhella PS, Hastings JL, Fujimoto N, et al. Impact of lifelong exercise "dose" on left ventricular compliance and distensibility. J Am Coll Cardiol 2014; 64: 1257-1266.

Gozna ER, Marble AE, Shaw A, et al. Age-related changes in the mechanics of the aorta and pulmonary artery of man. J Appl Physiol 1974; 36: 407-411.

Mackay EH, Banks J, Sykes B, et al. Structural basis for the changing physical properties of human pulmonary vessels with age. Thorax 1978; 33: 335-344.

Emirgil C, Sobol BJ, Campodonico S, et al. Pulmonary circulation in the aged. J Appl Physiol 1967; 23: 631-640.

Lam CS, Borlaug BA, Kane GC, et al. Age-associated increases in pulmonary artery systolic pressure in the general population. Circulation 2009; 119: 2663-2670.

van Empel VP, Kaye DM, Borlaug BA. Effects of healthy aging on the cardiopulmonary hemodynamic response to exercise. Am J Cardiol 2014; 114: 131-135.

Delclaux B, Orcel B, Housset B, et al. Arterial blood gases in elderly persons with chronic obstructive pulmonary disease (COPD). Eur Respir J 1994; 7: 856-861.

Blom H, Mulder M, Verweij W. Arterial oxygen tension and saturation in hospital patients: effect of age and activity. BMJ 1988; 297: 720-721.

Cerveri I, Zoia MC, Fanfulla F, et al. Reference values of arterial oxygen tension in the middle-aged and elderly. Am J Respir Crit Care Med 1995; 152: 934-941. 2053-2060.

Guenard H, Marthan R. Pulmonary gas exchange in elderly subjects. Eur Respir J 1996; 9: 2573-2577.

Continuous or nocturnal oxygen therapy in hypoxemic chronic obstructive lung disease: a clinical trial. Nocturnal Oxygen Therapy Trial Group. Ann Intern Med 1980; 93: 391-398.

Long term domiciliary oxygen therapy in chronic hypoxic cor pulmonale complicating chronic bronchitis and emphysema. Report of the Medical Research Council Working Party. Lancet 1981; 1: 681-686.

Crapo RO, Morris AH. Standardized single breath normal values for carbon monoxide diffusing capacity. Am Rev Respir Dis 1981; 123: 185-189.

Med 2010; 31: 528-538.

Wagner PD, Laravuso RB, Uhl RR, et al. Continuous distributions of ventilation-perfusion ratios in normal subjects breathing air and 100 per cent $\mathrm{O}_{2}$. J Clin Invest 1974; 54: 54-68.

Wagner PD, Saltzman HA, West JB. Measurement of continuous distributions of ventilation-perfusion ratios: theory. J Appl Physiol 1974; 36: 588-599.

Mellemgaard K. The alveolar-arterial oxygen difference: its size and components in normal man. Acta Physiol Scand 1966; 67: 10-20.

Raine JM, Bishop JM. A-a difference in $\mathrm{O}_{2}$ tension and physiological dead space in normal man. J Appl Physiol 1963; 18: 284-288.

Cardus J, Burgos F, Diaz O, et al. Increase in pulmonary ventilation-perfusion inequality with age in healthy individuals. Am J Respir Crit Care Med 1997; 156: 648-653.

Lumb AB, Nunn JF. Nunn's Applied Respiratory Physiology. 6th Edn. Elsevier Butterworth Heinemann, Edinburgh, 2005.

ohnson BD, Badr MS, Dempsey JA. Impact of the aging pulmonary system on the response to exercise. Clin Chest Med 1994; 15: 229-246.

Ball WC Jr, Stewart PB, Newsham LG, et al. Regional pulmonary function studied with xenon 133. J Clin Invest 1962; 41: 519-531.

Holland J, Milic-Emili J, Macklem PT, et al. Regional distribution of pulmonary ventilation and perfusion in elderly subjects. J Clin Invest 1968; 47: 81-92. electrical impedance tomography. Respir Physiol Neurobiol 2004; 143: 63-75.

Janssens JP. Aging of the respiratory system: impact on pulmonary function tests and adaptation to exertion. Clin Chest Med 2005; 26: 469-484.

Brischetto MJ, Millman RP, Peterson DD, et al. Effect of aging on ventilatory response to exercise and $\mathrm{CO}_{2}$. J Appl Physiol Respir Environ Exerc Physiol 1984; 56: 1143-1150.

1 Garcia-Rio F, Villamor A, Gomez-Mendieta A, et al. The progressive effects of ageing on chemosensitivity in healthy subjects. Respir Med 2007; 101: 2192-2198.

2 Kronenberg RS, Drage CW. Attenuation of the ventilatory and heart rate responses to hypoxia and hypercapnia with aging in normal men. J Clin Invest 1973; 52: 1812-1819.

3 Peterson DD, Pack AI, Silage DA, et al. Effects of aging on ventilatory and occlusion pressure responses to hypoxia and hypercapnia. Am Rev Respir Dis 1981; 124: 387-391.

4 Tack M, Altose MD, Cherniack NS. Effect of aging on respiratory sensations produced by elastic loads. $J$ Appl Physiol Respir Environ Exerc Physiol 1981; 50: 844-850.

5 Tack M, Altose MD, Cherniack NS. Effect of aging on the perception of resistive ventilatory loads. Am Rev Respir Dis 1982; 126: 463-467.

6 Faisal A, Webb KA, Guenette JA, et al. Effect of age-related ventilatory inefficiency on respiratory sensation during exercise. Respir Physiol Neurobiol 2015; 205: 129-139. 
Inbar O, Oren A, Scheinowitz M, et al. Normal cardiopulmonary responses during incremental exercise in 20- to 70-yr-old men. Med Sci Sports Exerc 1994; 26: 538-546.

Poulin MJ, Cunningham DA, Paterson DH, et al. Ventilatory response to exercise in men and women 55 to 86 years of age. Am J Respir Crit Care Med 1994; 149: 408-415.

Mummery HJ, Stolp BW, deL Dear G, et al. Effects of age and exercise on physiological dead space during simulated dives at 2.8 ATA. J Appl Physiol (1985) 2003; 94: 507-517.

Casaburi R, Whipp BJ, Wasserman K, et al. Ventilatory and gas exchange dynamics in response to sinusoidal work. J Appl Physiol Respir Environ Exerc Physiol 1977; 42: 300-301.

Casaburi R, Whipp BJ, Wasserman $\mathrm{K}$, et al. Ventilatory control characteristics of the exercise hyperpnea as discerned from dynamic forcing techniques. Chest 1978; 73: 2 Suppl, 280-283.

Babcock MA, Paterson DH, Cunningham DA. Effects of aerobic endurance training on gas exchange kinetics of older men. Med Sci Sports Exerc 1994; 26: 447-452.

Cunningham DA, Himann JE, Paterson DH, et al. Gas exchange dynamics with sinusoidal work in young and elderly women. Respir Physiol 1993; 91: 43-56.

Bell C, Paterson DH, Kowalchuk JM, et al. Oxygen uptake kinetics of older humans are slowed with age but are unaffected by hyperoxia. Exp Physiol 1999; 84: 747-759.

Casaburi R, Weissman ML, Huntsman DJ, et al. Determinants of gas exchange kinetics during exercise in the dog. J Appl Physiol Respir Environ Exerc Physiol 1979; 46: 1054-1060.

Hansen JE, Sue DY, Wasserman K. Predicted values for clinical exercise testing. Am Rev Respir Dis 1984; 129: S49-S55. Jones NL, Makrides L, Hitchcock C, et al. Normal standards for an incremental progressive cycle ergometer test. Am Rev Respir Dis 1985; 131: 700-708.

anssens JP, Pache JC, Nicod LP. Physiological changes in respiratory function associated with ageing. Eur Respir J 1999; 13: 197-205.

31: 521-527.

Lowery EM, Brubaker AL, Kuhlmann E, et al. The aging lung. Clin Interv Aging 2013; 8: 1489-1496.

Jensen D, Ofir D, O'Donnell DE. Effects of pregnancy, obesity and aging on the intensity of perceived breathlessness during exercise in healthy humans. Respir Physiol Neurobiol 2009; 167: 87-100.

Fowler RW, Pluck RA, Hetzel MR. Maximal expiratory flow-volume curves in Londoners aged 60 years and over. Thorax 1987; 42: 173-182.

Knudson RJ, Lebowitz MD, Holberg CJ, et al. Changes in the normal maximal expiratory flow-volume curve with growth and aging. Am Rev Respir Dis 1983; 127: 725-734.

Niewoehner DE, Kleinerman J. Morphologic basis of pulmonary resistance in the human lung and effects of aging. J Appl Physiol 1974; 36: 412-418.

Turner JM, Mead J, Wohl ME. Elasticity of human lungs in relation to age. J Appl Physiol 1968; 25: 664-671.

Frank NR, Mead J, Ferris BG Jr. The mechanical behavior of the lungs in healthy elderly persons. J Clin Invest 1957; 36: 1680-1687.

Pierce JA, Hocott JB. Studies on the collagen and elastin content of the human lung. J Clin Invest 1960; 39: 8-14. Babb TG, Rodarte JR. Mechanism of reduced maximal expiratory flow with aging. J Appl Physiol (1985) 2000; 89: 505-511.

Cummings SR, Melton LJ. Epidemiology and outcomes of osteoporotic fractures. Lancet 2002; 359: 1761-1767.

Edge JR, Millard FJ, Reid L, et al. The radiographic appearances of the chest in persons of advanced age. $\mathrm{Br} J$ Radiol 1964; 37: 769-774.

Estenne M, Yernault JC, De Troyer A. Rib cage and diaphragm-abdomen compliance in humans: effects of age and posture. J Appl Physiol (1985) 1985; 59: 1842-1848.

2007-2010. NCHS Data Brief 2012: 1-8.

Hedenstierna G, Santesson J. Breathing mechanics, dead space and gas exchange in the extremely obese, breathing spontaneously and during anaesthesia with intermittent positive pressure ventilation. Acta Anaesthesiol Scand 1976; 20: 248-254.

4 Naimark A, Cherniack RM. Compliance of the respiratory system and its components in health and obesity. J Appl Physiol 1960; 15: 377-382.

Pelosi P, Croci M, Ravagnan I, et al Total respiratory system, lung, and chest wall mechanics in sedated-paralyzed postoperative morbidly obese patients. Chest 1996; 109: 144-151.

Sjostrom L, Larsson B, Backman L, et al. Swedish obese subjects (SOS). Recruitment for an intervention study and a selected description of the obese state. Int J Obes Relat Metab Disord 1992; 16: 465-479.

Sin DD, Jones RL, Man SF. Obesity is a risk factor for dyspnea but not for airflow obstruction. Arch Intern Med 2002; 162: 1477-1481.

Enright PL, Kronmal RA, Manolio TA, et al. Respiratory muscle strength in the elderly. Correlates and reference values. Cardiovascular Health Study Research Group. Am J Respir Crit Care Med 1994; 149: 430-438.

Watsford ML, Murphy AJ, Pine MJ. The effects of ageing on respiratory muscle function and performance in older adults. J Sci Med Sport 2007; 10: 36-44.

Polkey MI, Harris ML, Hughes PD, et al. The contractile properties of the elderly human diaphragm. Am J Respir Crit Care Med 1997; 155: 1560-1564.

Tolep K, Higgins N, Muza S, et al. Comparison of diaphragm strength between healthy adult elderly and young men. Am J Respir Crit Care Med 1995; 152: 677-682.

Caskey CI, Zerhouni EA, Fishman EK, et al. Aging of the diaphragm: a CT study. Radiology 1989; 171: 385-389. McCool FD, McCann DR, Leith DE, et al. Pressure-flow effects on endurance of inspiratory muscles. J Appl Physiol (1985) 1986; 60: 299-303.

Tolep K, Kelsen SG. Effect of aging on respiratory skeletal muscles. Clin Chest Med 1993; 14: 363-378.

Kelly NG, McCarter RJ, Barnwell GM. Respiratory muscle stiffness is age- and muscle-specific. Aging (Milano) 1993; 5: 229-238.

Gosselin LE, Martinez DA, Vailas AC, et al. Passive length-force properties of senescent diaphragm: relationship with collagen characteristics. J Appl Physiol (1985) 1994; 76: 2680-2685. 
Gillooly M, Lamb D. Airspace size in lungs of lifelong non-smokers: effect of age and sex. Thorax 1993; 48: 39-43.

Fukuchi Y. The aging lung and chronic obstructive pulmonary disease: similarity and difference. Proc Am Thorac Soc 2009; 6: 570-572.

American Thoracic S, American College of Chest P. ATS/ACCP Statement on cardiopulmonary exercise testing. Am J Respir Crit Care Med 2003; 167: 211-277.

Edvardsen E, Scient C, Hansen BH, et al. Reference values for cardiorespiratory response and fitness on the treadmill in a 20- to 85-year-old population. Chest 2013; 144: 241-248.

Campbell SC. A comparison of the maximum voluntary ventilation with the forced expiratory volume in one second: an assessment of subject cooperation. J Occup Med 1982; 24: 531-533.

Sheel AW, Romer LM. Ventilation and respiratory mechanics. Compr Physiol 2012; 2: 1093-1142.

Johnson BD, Saupe KW, Dempsey JA. Mechanical constraints on exercise hyperpnea in endurance athletes. J Appl Physiol (1985) 1992; 73: 874-886.

Henke KG, Sharratt M, Pegelow D, et al. Regulation of end-expiratory lung volume during exercise. J Appl Physiol (1985) 1988; 64: 135-146.

Wilkie SS, Guenette JA, Dominelli PB, et al. Effects of an aging pulmonary system on expiratory flow limitation and dyspnoea during exercise in healthy women. Eur J Appl Physiol 2012; 112: 2195-2204.

Guenette JA, Dominelli PB, Reeve SS, et al. Effect of thoracic gas compression and bronchodilation on the assessment of expiratory flow limitation during exercise in healthy humans. Respir Physiol Neurobiol 2010; 170: 279-286.

7 Tessier JF, Nejjari C, Letenneur L, et al. Dyspnea and 8-year mortality among elderly men and women: the PAQUID cohort study. Eur J Epidemiol 2001; 17: 223-229.

Ofir D, Laveneziana P, Webb KA, et al. Sex differences in the perceived intensity of breathlessness during exercise with advancing age. J Appl Physiol (1985) 2008; 104: 1583-1593.

Guenette JA, Witt JD, McKenzie DC, et al. Respiratory mechanics during exercise in endurance-trained men and women. J Physiol 2007; 581: 1309-1322.

Guenette JA, Diane Lougheed M, Webb KA, et al. Can an 86-year-old woman with advanced lung disease be a world class athlete? Respir Physiol Neurobiol 2012; 181: 162-166. 